\title{
Onopordum cynarocephalum induces apoptosis and protects against 1,2 dimethylhydrazine-induced colon cancer
}

\author{
NAHED EL-NAJJAR ${ }^{1}$, NAJAT SALIBA ${ }^{2}$, SALMA TALHOUK $^{3}$ and HALA GALI-MUHTASIB ${ }^{1}$ \\ Departments of ${ }^{1}$ Biology, ${ }^{2}$ Chemistry and ${ }^{3}$ Plant Sciences, American University of Beirut, Beirut, Lebanon
}

Received August 25, 2006; Accepted November 11, 2006

\begin{abstract}
The potential chemopreventive properties of the crude extract of Onopordum cynarocephalum were evaluated. Growth inhibition was investigated in FHs74Int human normal intestinal cells and ModeK mouse normal intestinal cell line and in two human colon cancer cells HCT-116 (p53 $\left.3^{+/+}\right)$and HT-29 $\left(\mathrm{p} 53^{+-}\right)$. The extract was not cytotoxic to FHs74Int cells at concentrations 2-fold higher than the $\mathrm{IC}_{50}$ of HCT-116 cells. The extract inhibited dose-dependently the growth of HCT -116 cells $\left(\mathrm{IC}_{50}=0.18 \mathrm{mg} / \mathrm{ml}\right)$ to a greater extent than HT-29 cells $\left(\mathrm{IC}_{50}=1.8 \mathrm{mg} / \mathrm{ml}\right)$. The p53 wild-type HCT-116 cells were more sensitive than p53 mutant HT-29 cells to the pro-apoptotic effects of the plant extract; five times lower concentrations were needed to induce apoptosis in HCT-116 cells. Apoptosis induction by the extract was associated with an increase in the expression of pro-apoptotic proteins such as $\mathrm{p} 53$ and Bax, and a significant inhibition of the anti-apoptotic protein Bcl-2. Significant decrease in cyclin $\mathrm{D}_{1}$ protein and increase in p 21 protein was observed in extract-treated HCT-116 cells. In vivo, the crude extract injected intraperitoneally reduced the number of tumors by $64 \%(\mathrm{p}<0.0001)$ and decreased the mean size of aberrant crypt foci in the DMH model of colon cancer. These data collectively suggest that $O$. cynarocephalum has potential anti-colon cancer effects.
\end{abstract}

\section{Introduction}

Colon cancer is the most common gastrointestinal cancer and the fourth leading cause of cancer deaths in the world (1). Although surgical excision is the best option for treatment, many patients who undergo therapeutic resection will develop tumor recurrences. Therefore, there is an increasing urgency to develop strategies to prevent this disease (2).

Correspondence to: Dr Hala Gali-Muhtasib, Department of Biology, American University of Beirut, Beirut, Lebanon

E-mail: amro@aub.edu.lb

Key words: chemoprevention, aberrant crypt foci, apoptosis, cell cycle, herbal medicine
Medicinal herbs have been widely used in folk medicine to avoid the serious side effects of the available chemotherapeutics drugs. More than one-hundred plant species in Lebanon are reported to have medicinal properties, some of which have been commonly used by people as folk medicines for hundreds of years $(3,4)$. Among these are members of the Compositae family, which have been reported to treat a variety of human diseases (5-7). The root of the medicinal plant Aster tataricus has been shown to posses antitumor activities (6) while methanolic extracts from Tanacetum parthenium have been reported to have antimigraine activities (7).

Onopordum species are thistles of rough-grazing pasture that are distributed throughout the Mediterranean and semiarid areas of Eurasia and North Africa (8). Plants belonging to the genus Onopordum are members of the Compositae family that have been employed traditionally for their antibacterial, hemostatic, and hypotensive properties and for the treatment of skin cancer (9). Some of the biological activities of Onopordum genera include the augmentation of the NK cell activity $(10,11)$, the ability to change the rhythmic system by adjusting heart rate activity (12), and the inhibition of $\mathrm{TNF} \alpha$ and nitric oxide in murine endothelial cells (13). The biological activity of Onopordum is due to the presence of many secondary metabolites with flavonoids, lignans and sesquiterpene lactones being the most common constituents (9,14-16). Onopordum cynarocephalum (Compositae), the plant under investigation, is an endemic plant to the region and is used in folk medicine to treat various illnesses (4).

Despite the use of $O$. cynacorephalum in traditional medicine, the reported uses of the anticancer effects of this endemic species are limited. In this study, we explored the potential anticancer activities of the crude extract of $O$. cynarocephalum using human colon cancer cells and the 1,2-dimethylhydrazine $(\mathrm{DMH})$ mouse model of colon cancer. We have also attempted to identify the effects of the extract on cell cycle regulation and apoptosis signaling pathways in human colon cancer cells in order to elucidate its mechanism of antiproliferation.

\section{Materials and methods}

Cell culture. FHs74Int normal human intestinal epithelial cells, HCT-116 and HT-29 human colon cancer cells were kindly provided by Dr R. Schneider-Stock (Otto-von-Guericke University of Magdeburg, Germany). Normal mouse intestinal ModeK cells were kindly provided by Dr F. Homaidan 
(American University of Beirut, Lebanon). HCT-116 and HT-29 cells were grown in RPMI-1640 + HEPES. ModeK cells were cultured in DMEM low glucose. FHs74Int cells were grown in Hybricare medium (ATCC, Manassas, VA, USA). All cells were maintained at $37^{\circ} \mathrm{C}$ in a humidified atmosphere of $5 \% \mathrm{CO}_{2}, 95 \%$ air, supplemented with $1 \%$ penicillin-streptomycin $(100 \mathrm{U} / \mathrm{ml})$ and $10 \%$ fetal bovine serum (Invitrogen, Carlsbad, CA, USA). ModeK cells were supplemented with $1 \%$ non-essential amino acids. In all experiments, cells were plated at $10^{5}$ cells $/ \mathrm{ml}$; one day after seeding, the medium was changed and cells, at $40-50 \%$ confluency, were treated with different concentrations of the plant extract.

Plant material and extract preparation. Onopordum cynarocephalum was collected from Lebanon in summer 2002. Dr Stephen Jury (University of Reading, UK) identified the plant material and a voucher specimen has been deposited in the George Post Herbarium at the American University of Beirut (Beirut, Lebanon). The aerial parts were dried by leaving the plant sample in the shade for two weeks before grinding it into $\sim 10$-mm pieces using a blender. Twenty grams of the plant sample was placed in $160 \mathrm{ml}$ of boiled distilled water [material/solvent concentration (w/v) of 1:8] and shook for 20 min using an incubator shaker. The liquid extract was then collected by filtering the solid material through a cheese cloth (Sterile Gauze sponges 30x30 cm) to give a residue RII and a filtrate numbered 'II' and named the water crude extract (the volume of the filtrate is $\sim 120 \mathrm{ml}$ ). The extract was stored at $-20^{\circ} \mathrm{C}$ in well-sealed $150-\mathrm{ml}$ bottles covered with aluminum foil for bioassays. On the day of treatment, plant extracts were thawed at room temperature and added to the cells at different concentrations for $24 \mathrm{~h}$.

Cell proliferation and viability assays. Cells were plated in 96-well plates. One day after treatment, proliferation and toxicity were determined using the Cell Titer 96 non-radioactive cell proliferation kit and the CytoTox 96 non-radioactive cytotoxicity kit (Promega Corp., Madison, WI, USA). The proliferation assay is an MTT-based method, which measures the ability of metabolically active cells to convert tetrazolium salt into a blue formazan product, and its absorbance is recorded at $570 \mathrm{~nm}$. The CytoTox 96 assay quantitatively measures lactate dehydrogenase (LDH), a stable cytosolic enzyme that is released upon cell lysis. Released LDH in culture super-natants is measured with a coupled enzymatic assay which results in the conversion of a tetrazolium salt into a red formazan product, the absorbance of which is recorded at $490 \mathrm{~nm}$.

Flow cytometry analysis. Plant extract effects on cell proliferation were evaluated by measuring the distribution of cells in the different phases of the cell cycle by flow cytometry analysis. Cells were plated in 60-mm tissue culture dishes. One day post-treatment with the extract, cells were trypsinized, washed once with PBS, and fixed with $70 \%$ ethanol at least for $2 \mathrm{~h}$ at $-20^{\circ} \mathrm{C}$. Fixed cells were washed with PBS, incubated with $200 \mu \mathrm{g} / \mathrm{ml}$ RNase A for $1: 15 \mathrm{~h}$ at $37^{\circ} \mathrm{C}$ and stained with propidium iodide (PI) obtained from Molecular Probes (Eugene, OR, USA). The stained cells were analyzed by a FACScan flow cytometer, and the percentage of cells in
preG $G_{1}, G_{0} / G_{1}, S$ and $G_{2} / M$ phases was determined using the CellQuest Histogram analysis program. Cells that were less intensely stained than $\mathrm{G}_{1}$ cells in flow cytometric histograms were considered as apoptotic cells and marked as preG $_{1}$.

TUNEL assay. Terminal deoxy-transferase (tdT)-mediated dUTP nick-end labeling obtained from Roche Diagnostic Corp. (Mannheim, Germany) was used to assess the induction of apoptosis by measuring the extent of fragmented DNA. One day after treatment, cells were collected, washed twice with PBS, fixed with $4 \%$ formaldehyde diluted in 1X PBS (vol/ vol) at room temperature for $30 \mathrm{~min}$. The pellet was then washed with PBS and resuspended in $100 \mu 1$ of solution containing $1 \mathrm{X}$ PBS, $0.1 \%$ sodium citrate, and $0.1 \%$ Triton X-100 for 2 min. Fixed cells were then incubated with TUNEL reaction mixture. The stained cells were analyzed by a FACScan flow cytometer.

Western blot analysis. Cellular protein extracts were prepared from cells, washed twice with PBS, and scraped into SDSlysis buffer (0.25 M Tris- $\mathrm{HCl}, \mathrm{pH} 6.8,20 \%$ glycerol, 4\% SDS, $0.002 \%$ bromophenol blue, $10 \%$ ß-mercaptoethanol). Protein concentrations in each bioassay were determined using a DC protein assay kit (Bio-Rad Laboratories, Hercules, CA, USA) according to the manufacturer's protocol. Equal amounts of total cellular proteins $(40 \mu \mathrm{g})$ were resolved by $12 \%$ SDS-polyacrylamide gel electrophoresis, transferred onto polyvinylidene difluoride membranes (Amersham, Arlington, IL), and then probed with primary antibodies against actin (I-19), Bcl2 (N-19), p53 (FL-393), p21 [(c-19)-G)], cyclin $\mathrm{B}_{1}$ (H-344), and $\mathrm{Bax}$ and cyclin $\mathrm{D}_{1}$ followed by secondary antibody conjugated with horseradish peroxidase (all purchased from Santa Cruz, CA, USA). Actin was used to ensure equal loading. The immunocomplexes were visualized using enhanced chemiluminescent kits obtained from Santa Cruz.

\section{DMH tumor experiment}

Animals and treatment. Ninety-six female Balb/c mice, 6-9 week old, average weight $25 \mathrm{~g}$, were randomly distributed to the treatment and control groups. The mice were bred in the animal room of the Biology Department at the American University of Beirut. Mice were housed under optimum conditions of temperature set at $22 \pm 2^{\circ} \mathrm{C}$, with a 12-h light/ dark cycle. Mice were kept in plastic cages covered with sawdust and had unrestricted access to a commercial mouse $\operatorname{diet}(24 \%$ protein, $4.5 \%$ fat and $4 \%$ fiber) and tap water. All animal studies were conducted using a protocol approved by the Institutional Animal Care and Use Committee of the American University of Beirut. A total of 24 animals were included per treatment group. Four groups were used: Group 1 included mice injected intra-peritoneally (i.p.) with $0.9 \%$ sodium chloride. Group 2 included mice injected i.p. with the crude water extract of Onopordum cynarocephalum. Group 3 included mice injected subcutaneously with $20 \mathrm{mg} / \mathrm{kg}$ mouse body weight of the carcinogen DMH. Group 4 included mice injected i.p. with the crude extract 15 min prior to the injection of $\mathrm{DMH}$. DMH was dissolved in $0.9 \% \mathrm{NaCl}$ and was freshly prepared prior to injection. The duration of the experiment was 30 weeks and injections were done once/week. Volume 

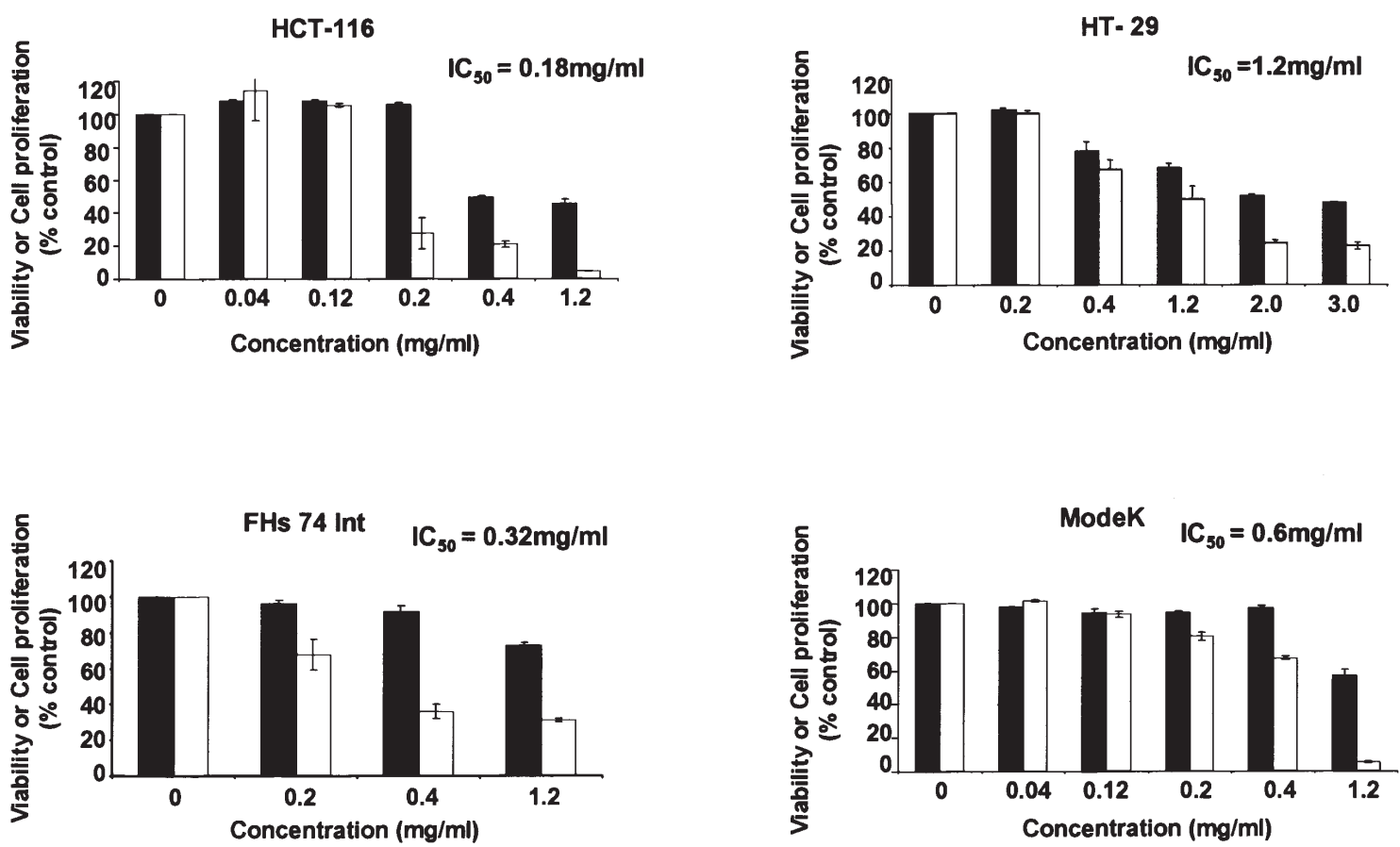

Figure 1. Effect of $O$. cynarocephalum crude extract on the viability and proliferation of HCT-116 (p53 $3^{+/+}$), HT-29 (p53 $3^{+/}$), FHs74Int human normal intestinal, and ModeK mouse normal intestinal cells. Cells were plated at $10^{5}$ cells $/ \mathrm{ml}$. One day after seeding, cells were treated at $50 \%$ confluency with increasing concentrations of extract. Cell growth and viability were determined at $24 \mathrm{~h}$ using the Cell Titer 96 non-radioactive cell proliferation kit and the CytoTox 96 non-radioactive cytotoxicity kit, respectively. Each value represents the mean \pm SD of two separate experiments performed in triplicate.

of injected solution (saline or extract) was $0.3 \mathrm{ml}$. The long-term animal tumor experiment was performed with the undiluted crude extract which was not toxic to animals when injected i.p. for 10 consecutive days (data not shown).

Tumor and aberrant crypt foci counts. At week 10, mice were sacrificed by ether inhalation and colon tissue was processed for determining ACF counts $(n=8)$ by staining with Schiff's reagent. Briefly, the colons were excised, flushed with PBS, and kept in ethanol:acetic acid $(3: 1)$ at $4^{\circ} \mathrm{C}$ until analysis. At the time of analysis, colons were placed in $50 \%$ aqueous ethanol for $15 \mathrm{~min}$ at room temperature, transferred to distilled water for $10 \mathrm{~min}$, then to $1 \mathrm{~N} \mathrm{HCl}$ at $60^{\circ} \mathrm{C}$. After $7 \mathrm{~min}$ of incubation, colons were transferred to the Schiff's reagent for $10 \mathrm{~min}$. They were then rinsed in distilled water, cut longitudinally, pinned flat on a corkboard, and stored overnight in $45 \%$ aqueous acetic acid at $4^{\circ} \mathrm{C}$. The following day, all colons were cut into equal parts (proximal, middle and distal), and placed on microscopic slides and examined using fluorescent microscopy. ACF were identified, as being larger in diameter and having thickened crypt walls compared to neighboring normal crypts, and their size and location were recorded.

At weeks 20 and 30, colon tissue was processed for the determination of tumor numbers $(n=8)$. Briefly, the colons were excised, flushed with PBS, rinsed with distilled water, cut longitudinally and visible tumors were counted using an optical microscope.

Statistical analysis. Results are expressed as means \pm standard error (SE). Statistical analysis was performed using SPSS Student Version 11.0 Software Package. Comparisons between
Groups 4 and 3 were evaluated using ANOVA followed by Dunnett test. The level of significance was set at 0.05 . For all tests, $\mathrm{p}<0.05$ was considered as significant.

\section{Results}

Onopordum cynarocephalum crude extract inhibits cancer cell proliferation. The water extract of $O$. cynarocephalum exerted differential inhibitory effects on FHs74Int $\left(\mathrm{IC}_{50}=0.3 \mathrm{mg} / \mathrm{ml}\right)$ and ModeK $\left(\mathrm{IC}_{50}=0.6 \mathrm{mg} / \mathrm{ml}\right)$ cells (Fig. 1). The plant extract was more cytotoxic to colon cancer cells than to normal intestinal cells. The extract inhibited cancer cell proliferation in a dose-dependent manner. HCT-116 (p53 $\left.3^{++}\right)$cells were more sensitive to the growth inhibitory effects of the extract than HT-29 (p53+/) cells. In fact, the $\mathrm{IC}_{50}$ of HCT-116 $\left(\mathrm{p} 53^{+/+}\right)$cells was 9 times higher than HT-29 (p53 $\left.3^{+/}\right)$cells (Fig. 1).

Onopordum cynarocephalum crude extract induces cell cycle arrest and apoptosis. As a next step, we investigated the mode of action of the extract on cellular parameters, including cell cycle distribution and apoptosis induction in the two cancer cell lines. For each cell line, we used concentrations of the extract that range below and above the $\mathrm{IC}_{50}$ to examine cell cycle regulatory effects. The cycling profiles of cells treated with graded concentrations of the extract were obtained by PI staining of DNA content using flow cytometric analysis.

The apoptotic effect of the extract was more pronounced in HCT-116 (p53 $3^{+/+}$) cells than in HT-29 (p53+/) cells (Fig. 2). Ten-fold higher concentrations of the crude extract were needed to induce comparable levels of apoptosis in HT-29 


\section{HCT-116 cells}
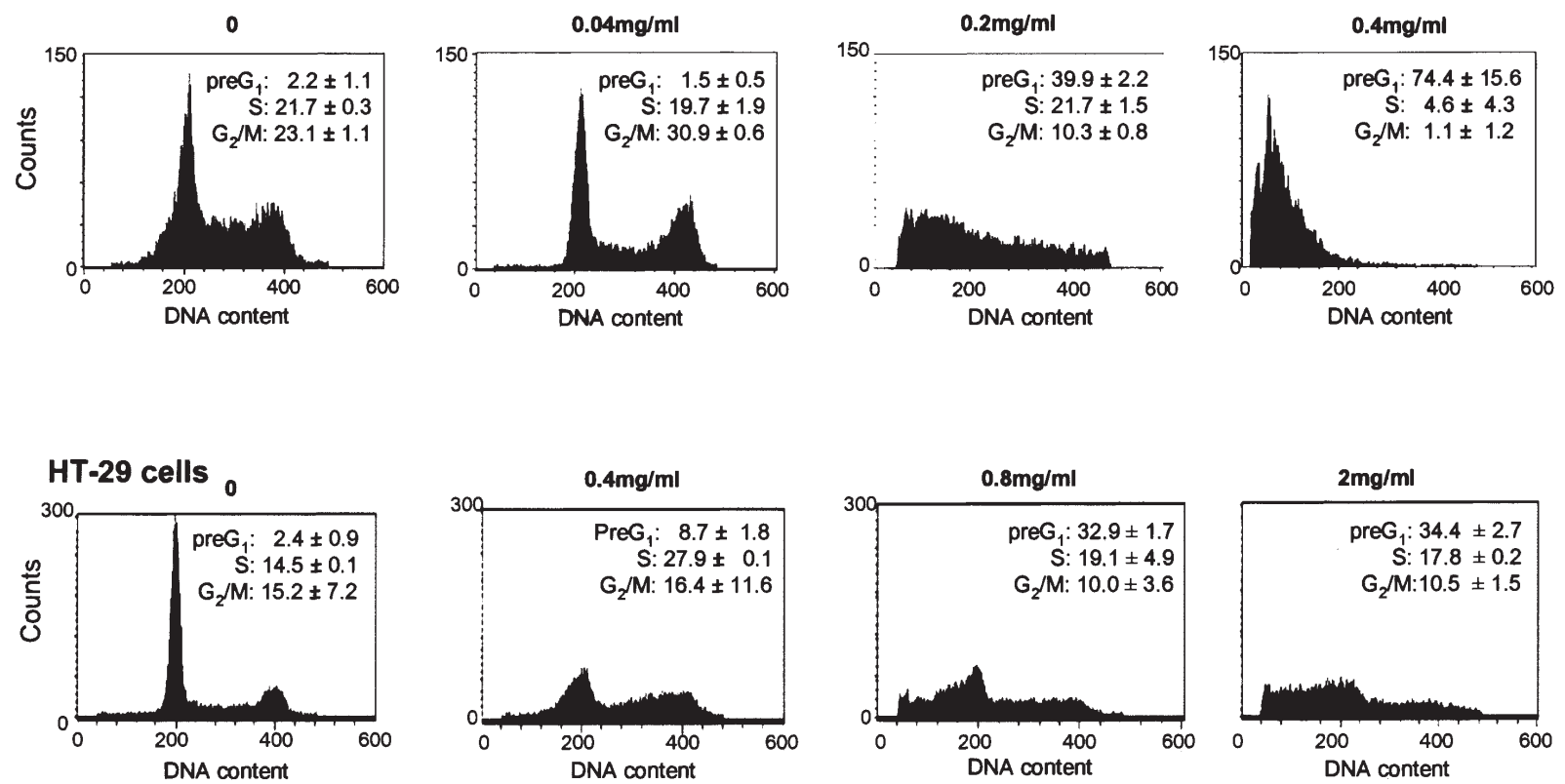

Figure 2. Effect of $O$. cynarocephalum crude extract on cell cycle progression in HCT-116 and HT-29 cells. Cells were plated at $10^{5}$ cells $/ \mathrm{ml}$. One day after seeding, cells were treated at 50\% confluency with increasing concentrations of the extract for $24 \mathrm{~h}$ and harvested and stained with propidium iodide. Distribution of the cells in $\mathrm{preG}_{1}, \mathrm{~S}$ and $\mathrm{G}_{2} / \mathrm{M}$ phases was analyzed by flow cytometry as described in Materials and methods. Each value represents the mean \pm SD of two separate experiments performed in duplicate.
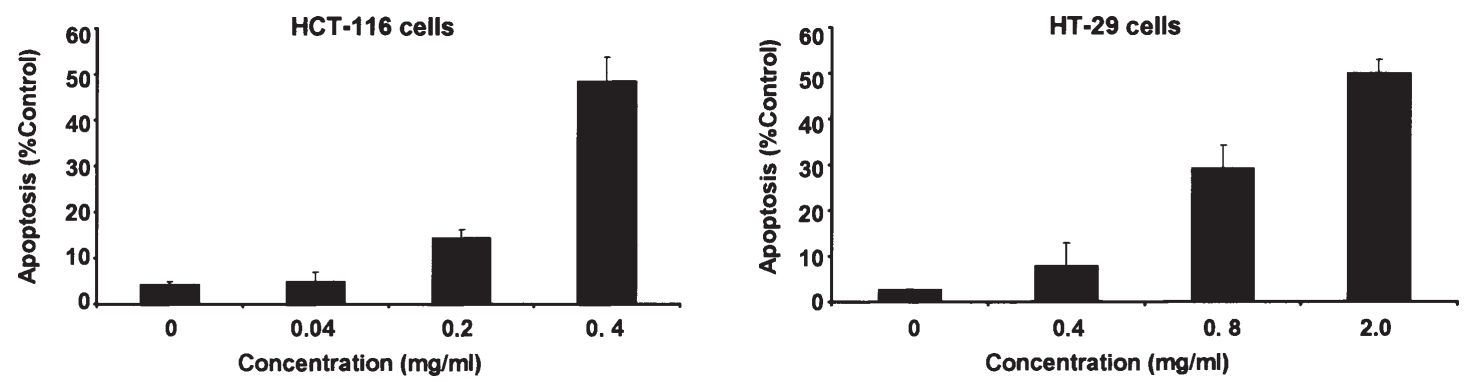

Figure 3. Effect of $O$. cynarocephalum crude extract on apoptosis-induction in HCT-116 and HT-29 cells. Cells were plated at $10^{5}$ cells $/ \mathrm{ml}$. One day after seeding, cells were treated at 50\% confluency with increasing concentrations of the extract for $24 \mathrm{~h}$. The induction of apoptosis was determined using TUNEL assay as described in Materials and methods. Each value represents the mean \pm SD of two separate experiments performed in duplicate.

cells. In addition, the extract induced $\mathrm{S}$ phase arrest at lower concentrations in HT-29 cells (Fig. 2).

The nature of the observed cell death was investigated by utilizing the TUNEL assay, which confirmed that the induced increases in the sub- $\mathrm{G}_{1}$ fractions were due to apoptosis induction. In comparison with untreated HCT-116 cells, extract-treated cells underwent significant amount of apoptosis (Fig. 3); 50\% apoptotic cells appeared with the use of $0.4 \mathrm{mg} / \mathrm{ml}$ of the extract. Furthermore, HT-29 cells treated with $2 \mathrm{mg} / \mathrm{ml}$ showed $50 \%$ induction of apoptosis as compared to the control cells (Fig. 3).

Onopordum cynarocephalum extract modulates key cell cycle and apoptosis regulators. We further investigated the effects of the plant extracts on the expression of key cell cycle mediators that accompany cell cycle arrest and apoptosis; these include p53, p21, cyclins $\left(D_{1}\right.$ and $\left.B_{1}\right)$, Bax and Bcl-2. Cyclin $D_{1}$ is known to associate with CDK4 and CDK6 to form holo- enzyme complexes that phosphorylate $\mathrm{pRB}$ and ensure $\mathrm{G}_{1}-\mathrm{S}$ transition while cyclin $B_{1}$ is a protein known to regulate cdc2 kinase activity and ensure $\mathrm{G}_{2} / \mathrm{M}$ transition. Upon treating HCT-116 cells with 0.2 and $0.4 \mathrm{mg} / \mathrm{ml}$ of the extract, we observed a dose-dependent decrease in the expression of cyclin $\mathrm{B}_{1}$ ranging from $80-90 \%$ in addition to a decrease in cyclin $\mathrm{D}_{1}$ expression (Fig. 4). Furthermore, an increase in the expression of the tumor suppressor protein p53 (1.5- to 2-fold) and of the cyclin-dependent kinase inhibitor p21 (1.5-fold) was observed (Fig. 4). Treatment of HCT-116 cells with the plant extract led to an increase in the $\mathrm{Bax} / \mathrm{Bcl}-2$ ratio; an increase in this ratio is a fundamental event in apoptosis induction. Interestingly, a 30-fold increase in $\mathrm{Bax} / \mathrm{Bcl}-2$ ratio in HCT-116 cells was observed with $0.4 \mathrm{mg} / \mathrm{ml}$ of the extract (Fig. 4).

Onopordum cynarocephalum or DMH have no effect on body weight gain in mice. Intra-peritoneal injections of mice with 
A

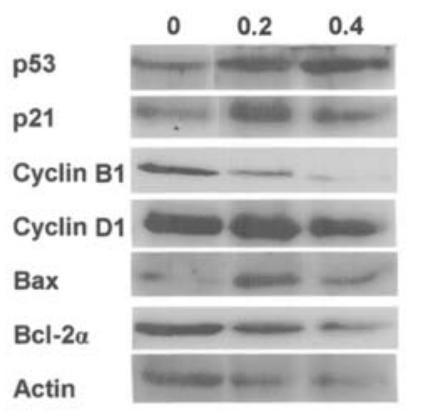

B

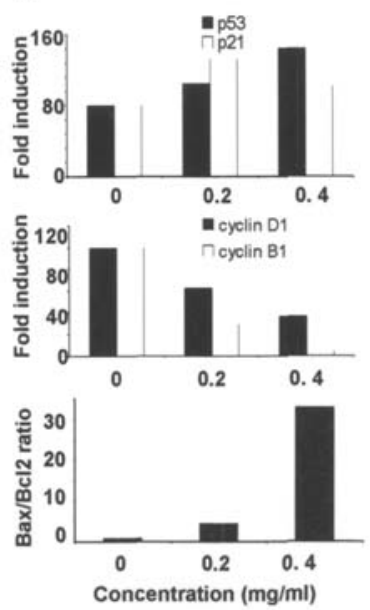

Figure 4. Effects of $O$. cynarocephalum crude extract on the expression profile of cell cycle regulatory proteins; namely p21, p53, Bax, Bcl-2, cyclin $\mathrm{D}_{1}$ and cyclin $\mathrm{B}_{1}(\mathrm{~A})$. HCT-116 cells were treated at $50 \%$ confluency with various concentrations of the extract for $24 \mathrm{~h}$. Cell lysis and Western blotting were performed as described in Materials and methods. Bands were quantified and are expressed as percentage of control cells (B).

the non-diluted crude extracts of $O$. cynarocephalum for 10 consecutive days did not affect their body weight or result in their death (data not shown). Therefore, we performed the long-term animal tumor experiment with the undiluted crude extracts. In addition, DMH-injected groups gained body weight during the entire experimental period (data not shown).
Onopordum cynarocephalum inhibited ACF formation in the middle colon and inhibited ACF sizes. Following Schiff's reagent staining at week 10 in proximal, middle and distal segments, no ACF were observed in animals injected with the plant extract alone or those injected with saline. In the mice receiving DMH only, all animals developed ACF. ACF were distinguished from normal crypts by their darker staining and larger size, elliptical shape, and thicker epithelial lining. The numbers of ACF were significantly higher in the middle colon than in the distal colon and none were found in the proximal colon. The injection of the crude extract of $O$. cynarocephalum 15 min prior to $\mathrm{DMH}$ injection reduced to a greater extent the number of ACF in the middle than in the distal colon $(\mathrm{p}<0.05)$ but did not decrease the average number of $\mathrm{ACF} /$ colon as compared to the carcinogen-treated group (Fig. 5A). However, the average sizes of ACF located in all parts of the colon were significantly inhibited $(\mathrm{p}<0.05)$ in mice injected with the extract (Fig. 5B). The degree of size inhibition in the middle colon, which represented the most populated part with ACF, was greater than the distal colon.

Onopordum cynarocephalum inhibited tumor formation in DMH-induced colon cancer. At 20 and 30 weeks of treatment and using an optical microscope, tumors were observed in all DMH-treated mice. No such lesions were noted in animals treated with either plant extract or saline alone (data not shown). Interestingly, a significant inhibition of tumor formation was observed in the animal groups injected with the extract prior to DMH treatment. The extent of tumor inhibition was $65 \%(\mathrm{p}<0.001)$ at week 20 and $63 \%(\mathrm{p}<0.0001)$

A

\begin{tabular}{|c|c|c|c|}
\cline { 2 - 4 } \multicolumn{1}{c|}{} & \multicolumn{3}{c|}{ Average No. of ACF/colon \pm SE } \\
\cline { 2 - 4 } \multicolumn{1}{c|}{} & \multicolumn{3}{c|}{ Location } \\
\hline Treatment & Middle & Distal & Total \\
\hline DMH only & $24 \pm 2.2$ & $12 \pm 0.9$ & $36 \pm 1.5$ \\
\hline DMH + extract & $18 \pm 0.9^{\circ}$ & $15 \pm 2.1$ & $33 \pm 1.5$ \\
\hline
\end{tabular}

B

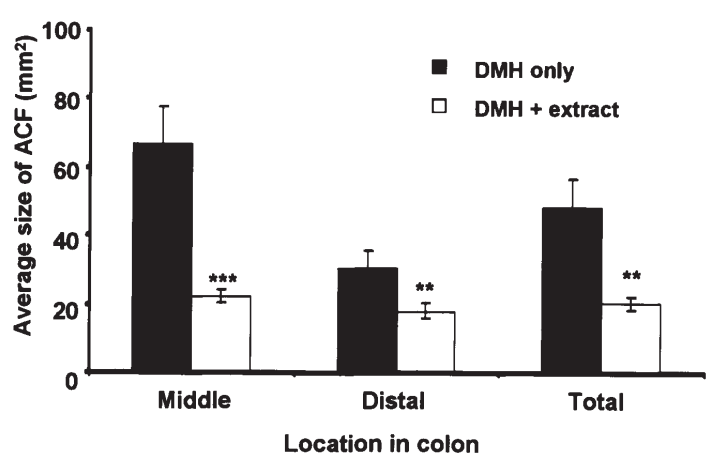

C

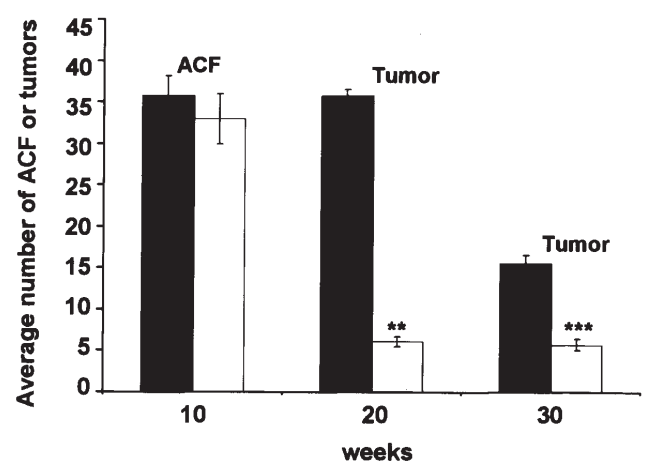

Figure 5. Effect of DMH, and crude Onopordum extract on (A) the number of ACF, (B) the sizes of ACF and (C) the number of tumors at weeks 20 and 30. $\mathrm{DMH}$ alone represents the positive control. "Statistically significant as compared to the DMH group. The mean difference is significant at the 0.05 level. ${ }^{*} \mathrm{p}<0.03,{ }^{* *} \mathrm{p}<0.001,{ }^{* * *} \mathrm{p}<0.0001$ 
at week 30 in extract-injected mice as compared to the DMH group (Fig. 5C).

\section{Discussion}

Plant-based products have been known to prevent the development of colon cancer (17). In this study, we have investigated the ability of $O$. cynarocephalum, a plant indigenous to the Mediterranean region, to inhibit growth, and induce cell cycle arrest and apoptosis in two human colon cancer cell lines that differ in their p53 status. In addition, we have used an established model of DMH-induced colorectal carcinogenesis to assess the chemopreventive activity of the plant extract when administered intra-peritoneally to mice. Treatment of HCT-116 cells with the extract inhibited their growth dose-dependently at concentrations that showed no apparent cytotoxic effects in two normal intestinal cell lines. Flow cytometric analysis revealed that the induction of apoptosis by the extract is a dose-dependent process. Interestingly, the p53 wild-type HCT-116 cells were more sensitive to the growth inhibitory and pro-apoptotic effects of the extract than the p53 mutant HT-29 cells. Five times higher concentrations were required to induce comparable levels of apoptosis in HT-29 cells. The pro-apoptotic effect of the extract observed in the p53 mutant HT-29 cell line is significant in light of the fact that p53 mutations occur in the majority of human cancers.

Extract-mediated cell cycle arrest and apoptosis correlated well with its ability to differentially modulate the expression of components of the signaling pathways involved in cell cycle arrest and apoptosis. p53, a tumor suppressor protein, protects mammals from neoplasia by inducing cell cycle arrest, DNA repair, and apoptosis by activation of its downstream effectors p21, Gadd45 and Bax. This activation occurs in response to a variety of stresses such as DNA damage, hypoxia and chemotherapeutic drugs (18). Extracttreated HCT-116 cells manifested a dose-dependent increase in p53 protein levels. This increase correlated well with the increase in the expression levels of p21 and Bax proteins. Up-regulation of Bax and down-regulation of Bcl-2 would favor the pro-apoptotic over the anti-apoptotic response in cells, leading to the release of cytochrome $\mathrm{c}$ and inducing programmed cell death. Interestingly, the significant increase in the $\mathrm{Bax} / \mathrm{Bcl}-2$ ratio in extract-treated HCT-116 cells correlated with the induction of apoptosis observed by flow cytometry analysis. The deregulation of cell cycle regulators is one of the most common events in tumor development. Numerous studies have indicated that $\mathrm{G}_{1}$ cyclins are frequently deregulated in colorectal cancer (19). Cyclin $\mathrm{D}_{1}$ protein has been classified as a $G_{1}$ cyclin and occupies a nodal position in the regulation of the cell cycle. Overexpression of cyclin $\mathrm{D}_{1}$ plays a contributory role in the multistep process of colorectal carcinogenesis (20). Our finding that the extract of $O$. cynarocephalum inhibited cyclin $\mathrm{D}_{1}$ protein expression and increased the expression levels of the cyclin-dependent kinase inhibitor $\mathrm{p} 21$ protein correlates well with the observed cell growth inhibition. In addition, the extract significantly inhibited cyclin $B_{1}$ protein expression, the destruction of which is fundamental for mitotic exit and cytokinesis (21).

Unlike most known chemotherapeutic drugs associated with strong toxicity, O. cynarocephalum showed high selectivity against cancer cells with no apparent toxic effects on normal cells. This differential effect makes the plant extract a potentially harmless chemopreventive agent that can effectively inhibit colon cancer development. The stepwise development of colorectal carcinogenesis from dysplastic ACF to adenomas and adenocarcinomas offers multiple opportunities for assessment and intervention, particularly in animal models. Experimental colonic tumors induced by DMH are of epithelial origin with a similar histology, morphology, and anatomy to human colonic neoplasms and therefore, are regarded as excellent models for chemopreventive studies (22). DMH-induced colon cancer has been used extensively to study the inhibitory effect of plant-derived materials. For instance, oral administration of Brussels sprouts as juice or intact freeze-dried tissues to male Wistar rats induces apoptosis, suppresses cell division of the colonic crypt and inhibits ACF numbers in DMH-induced colon cancer (23). In addition, an extract of soybeans containing the Bowman-Birk protease inhibitor added to the diet of mice treated with DMH significantly suppresses carcinogen-induced adenomatous tumors in the colonic mucosa (24).

The possible tumor inhibitory effect of $O$. cynarocephalum in $\mathrm{DMH}$-induced colorectal carcinogenesis was investigated by treating mice weekly with the extract prior to $\mathrm{DMH}$ injection. After DMH injections over a 10-week period, $100 \%$ of the mice treated with both $\mathrm{DMH}$ and $\mathrm{DMH}+$ plant extract developed ACF in the colon, with the majority of ACF found in the middle colon. ACF are potential markers of early tumor growth and are considered to be useful intermediate biomarkers for the modifying effect of certain natural or synthetic compounds on chemically induced carcinogenesis (25). The decrease in the average number of ACF in the colon by the extract was not statistically significant. However, the extract significantly suppressed $(\mathrm{p}<0.05)$ the average number of $\mathrm{ACF}$ in the middle colon when comparing the inhibitory effect in the middle to distal colon (Fig. 5A). Despite the absence of the extract's inhibitory effect on ACF number, it reduced notably the mean size of ACF $(p<0.001)$. The presence of the majority of tumors in the middle and distal colon as compared to the proximal part is in agreement with other findings $(26,27)$.

Interestingly, at week 20,65\% inhibition of tumor formation was associated with the use of the extract $(\mathrm{p}<0.001)$, while at week 30 , tumor formation was reduced by $63 \%(\mathrm{p}<0.0001)$. The inhibitory effect on tumor formation (weeks 20 and 30) and not on ACF development (week 10) suggests that the extract may be active at later stages of tumor development rather than at the initiation stage. This activity resembles that of rofecoxib, a highly selective inhibitor of cyclooxygenase- 2 that was shown to inhibit the later stages of DMH-induced colon carcinogenesis in Wistar rats (28).

This study shows for the first time the potent antiproliferative effects of $O$. cynarocephalum against colon cancer. The crude extract inhibited the growth of human colon cancer cells by inducing cell cycle arrest and apoptosis. In the HCT-116 cell line, the induction of apoptosis was mediated by the proapoptotic proteins $\mathrm{p} 53$ and $\mathrm{Bax}$, and associated with an inhibition of the anti-apoptotic protein $\mathrm{Bcl}-2$. In addition, a decrease in cyclins $\mathrm{B}_{1}$ and $\mathrm{D}_{1}$, and an increase in the cyclindependent kinase inhibitor p21 were observed. In vivo, this 
extract inhibited the mean size of $\mathrm{ACF}$ and reduced tumor formation in the DMH model of colon cancer. These findings collectively indicate that $O$. cynarocephalum is a plant with potential anti-colon cancer effects.

\section{Acknowledgements}

This study was funded by a grant from Merci Corps/USDA made to the Initiative of Biodiversity Studies in Arid Regions (IBSAR) at the American University of Beirut. We thank members of the Central Research Science Laboratory for their help in using the flow cytometer and fluorescence microscope.

\section{References}

1. Delage B, Groubet R, Pallet V, Barras C, Higueret P and Cassand P: Vitamin A prevents high fat diet-induced ACF development and modifies the pattern of expression of peroxisome proliferator and retinoic acid receptor m-RNA. Nutr Cancer 48: 28-36, 2004

2. Park HS, Cho HY, Ha YL, Park JH and Park Y: Dietary conjugated linoleic acid increases the mRNA ratio of Bax/Bcl-2 in the colonic mucosa of rats. J Nutr Biochem 15: 229-235, 2004.

3. Rouwayha A: Herbal treatment. Dar El Qualam Beirut, Lebanon, 1983.

4. Rouwayha A: Alatadawi Bil Aa'shab. Dar El Qualam Beirut, Lebanon, 1981.

5. Cozzolino R, Palladino P, Rossie F, Cali G, Benedetti E and Laccetti P: Antineoplastic cyclic astin analogues kill tumor cells via caspase-mediated induction of apoptosis. Carcinogenesis 26: 733-739, 2005.

6. Tassorelli C, Greco R, Morazzoni P, Riva A, Sandrini G and Nappi G: Parthenolide is the component of tanacetum parthenium that inhibits nitroglycerin-induced Fos activation: studies in an animal model of migraine. Cephalalgia 25: 612-621, 2005.

7. Pandey MM, Govinrarajan R, Rawat AK and Pushpangadan P: Free radical scavenging potential of Saussarea costus. Acta Pharmaceutica 55: 297-304, 2005.

8. Rees M, Sheppard A, Briese D and Mangel M: Evolution of size-dependent flowering in Onopordum illyricum: a quantitative assessment of the role of stochastic selection pressures. Am Nat 154: 628-651, 1999.

9. Braca A, De Tommasi N, Moreillei I and Pizza C: New metabolites from Onopordum illyricum. J Nat Prod 62: 1371-1375, 1999.

10. Abuharfeil NM, Maraqa A and von Kleist S: Augmentation of natural killer cell activity in vitro against tumor cells by some wild plants from Jordan. J Ethnopharmacol 71: 55-63, 2000.

11. Abuharfeil NM, Salim M and von Kleist S: Augmentation of natural killer cell activity in vivo against tumor cells by some wild plants from Jordan. Phytother Res 15: 109-113, 2001.

12. Cysarz D, Schurholz T, Bettermann H and Kummel HC: Evaluation and modulation in heart rate variability caused by a composition of herbal extracts. Drug Res 50: 421-424, 2000 .
13. Strzelecka M, Bzowska M, Koziel J, Szuba B, Dubiel O, Rivera D, Heinrich $\mathrm{M}$ and Bereta J: Anti-inflammatory effects of extracts from some traditional Mediterranean diet plants. J Physiol Pharmacol 56: 139-156, 2005.

14. Cardona L, Aleman RA, Begona G and Pedro JR: Sesquiterpenes, flavonoids and lignans from Onopordon acaulon. Phytochemistry 31: 3630-3632, 1992.

15. Lazari D, Begona G, Skaltsa H, Pedro JR and Harvala C: Sesquiterpene lactones from Onopordon laconicum and $\mathrm{O}$. sibthorpianum. Phytochemistry 47: 415-422, 1998.

16. EL-Moghazy SA, Ahmed AA, Abdel-Ghani HF and ElShanawany MA: A new eudesmane derivative from Onopordon ambiguum. Fitoterapia 73: 97-98, 2002.

17. Gali-Muhtasib HU, Diab-Assaf M, Bolitze C, Al-Hmaira J, Hartig R, Roessner A and Schneider-Stock R: Thymoquinone extracted from black seed triggers apoptotic cell death in human colorectal cancer cells via a p53-dependent mechanism. Int J Oncol 25: 857-866, 2004.

18. Taylor WR and Stark GR: Regulation of the G2/M transition by p53. Oncogene 20: 1803-1815, 2001.

19. Maeda K, Chung YS, Kang SM, Ogawa M, Onoda N, Nishiguchi Y, Ikehara T, Nakata B, Okuno M and Sowa M: Cyclin D1 overexpression and prognosis in colorectal adenocarcinoma. Oncology 55: 145-151, 1998.

20. Weinstein IB, Begemann M, Zhou P, Han EK, Sgambato A, Doki Y, Arber N, Ciaparrone M and Yamamoto H: Disorders in cell circuitry associated with multistage carcinogenesis: exploitable targets for cancer prevention and therapy. Clin Cancer Res 3: 2696-2702, 1997.

21. Takizawa CG and Morgan DO: Control of mitosis by changes in the subcellular location of cyclin B1-CDK1 and Cdc25C. Curr Opin Cell Biol 12: 656-658, 2000.

22. Maskens AP: Histogenesis and growth pattern of 1,2-dimethylhydrazine-induced rat colon adenocarcinoma. Cancer Res 36 1585-1592, 1976.

23. Smith TK, Mitchen R and Johnson IT: Effects of Brassica vegetable juice on the induction of apoptosis and aberrant crypt foci in rat colonic mucosal crypts in vivo. Carcinogenesis 24: 491-495, 2003.

24. Weed HG, McGandy RB and Kennedy AR: Protection against dimethylhydrazine induced adenomatous tumors of the mouse colon by the dietary addition of an extract of soybeans containing the Bowman-Birk protease inhibitor. Carcinogenesis 6: 1239-1241, 1985.

25. Archana S, Samit G and Sukta D: Modulatory influence of garlic and tomato on cyclooxygenase-2 activity, cell proliferation and apoptotis during azoxymethane induced colon carcinogenesis in rat. Cancer Lett 208: 127-136, 2004

26. Rodrigues MAM, Silva LAG, Salvadori DMF, De Camargo JLV and Montenegro MR: Aberrant crypt foci and colon cancer: comparison between a short- and medium-term bioassay for colon carcinogenesis using dimethylhydrazine in wistar rats. Braz J Med Biol Res 35: 351-355, 2002.

27. Ma QY, Williamson KE and Rowlands BJ: Variability of cell proliferation in the proximal and distal colon of normal rats and rats with dimethylhydrazine induced carcinogenesis. World $\mathbf{J}$ Gastroenterol 8: 847-852, 2002.

28. Perse M, Zeibic A and Cerar A: Rofecoxib does not inhibit aberrant crypt foci formation but inhibits later steps in the development of experimental colorectal cancer: rofecoxib in experimental colon cancer. Scand J Gastroenterol 40: 61-67, 2005. 